\title{
КЛ-1 \\ СОЗДАНИЕ НОВЫХ НЕПОДВИЖНЫХ ФАЗ ДЛЯ ХРОМАТОГРАФИИ ПУТЕМ СИНТЕЗА ВНУТРИ КОЛОНКИ
}

\author{
Патрушев Ю.В. ${ }^{1,2}$
}

${ }^{1}$ ФГБУН ФИЦ Институт катализа им. Г. К. Борескова СО РАН, Новосибирск, Россия

${ }^{2}$ Новосибирский национальный исследовательский государственный университет, Новосибирск, Россия

patrush@catalysis.ru

DOI: 10.26902/ASFE-11_12

Хроматографическая колонка - основной элемент хроматографической системы. Классические способы создания хроматографических колонок подразумевают использование готовых неподвижных фаз (жидкости или твердые сорбенты), которые тем или иным способом помещают внутрь колонки. Основным способом приготовления капиллярных колонок для газовой хроматографии является статический метод низкого давления, когда готовая неподвижная фаза наносится на колонку из раствора в летучем растворителе. Этот метод используют коммерческие производители для приготовления высокоэффективных колонок с неподвижными жидкими фазами. Однако для приготовления пористослойных колонок для газоадсорбционной хроматографии данный способ имеет серьезные ограничения, связанные с нерастворимостью большинства пористых материалов.

Современные колонки для высокоэффективной жидкостной хроматографии (ВЭЖХ) получают методом плотной упаковки сферических частиц готового сорбента диаметром 25 мкм из суспензии под высоким давлением. Чем меньше диаметр частиц, тем более плотная упаковка и выше эффективность колонки. Но при этом существенно повышается перепад давления на колонке, что приводит к перераспределению частиц и нежелательным тепловым градиентам.

Прямой синтез хроматографического материала внутри колонки позволяет создавать сорбенты с заранее заданными свойствами, такими как селективность и текстурные характеристики. В колонке возможно синтезировать как неорганические материалы, так и пористые полимеры органической природы. Удобным способом для создания капиллярных пористослойных газохроматографических колонок является золь-гель технология. Колонка заполняется раствором предшественника (например, тетраэтоксисилана), после чего начинается реакция гидролиза и поликонденсации. На внутренней стенке капилляра образуется монолитная пленка пористого силикагеля. В зависимости от природы предшественника можно получать пористые слои с различными свойствами. Если в зольгель реакции участвует компонент с органической группой, можно получать органонеорганические сорбенты с различной хроматографической селективностью.

Неподвижные фазы для ВЭЖХ, синтезированные непосредственно в колонке, представляют собой монолитные сорбенты. В отличие от насадочных колонок монолитный сорбент является единым ковалентно связанным материалом, заполняющим весь доступный объем колонки. Элюент в такой колонке движется по специальным транспортным порам, пронизывающим колонку по всей длине. Монолит может иметь неорганическую или органическую природу. Очевидные преимущества монолитных сорбентов связаны с высокой проницаемостью такой колонки.

Синтез сорбента непосредственно в хроматографической колонке позволяет расширить набор неподвижных фаз с различными химическими свойствами и текстурными характеристиками, а, следовательно, позволяет решать проблему выбора колонки для конкретной задачи разделения. 